\title{
A Survey on Ubiquitous Computing: Towards Empowering Wireless Network Technologies
}

\author{
Ahmed EIShafee \\ Asst. Professor, Faculty of Engineering, \\ Electrical Engineering. Dept, \\ Ahram Canadian University \\ 6th October City, Giza, Egypt
}

\begin{abstract}
Nowadays Wireless Communications are widely embedded in various ubiquitous computing models and applications. Ubiquitous computing is considered as a new technology paradigm that should be probed as one of Wireless Communications recent implementations. Ubiquitous computing, pervasive computing, everyware computing, ambient intelligence, haptic computing, and Internet of Things are all aliases to one technology where systems are available anywhere and anytime, to anyone, where and when needed. Practically, the differences between these terms is of an academic nature; they are commonly aiming to the goal of assisting people as well as the continuous improvement and promotion of economic and social processes by taking advantages of communicating with numerous microprocessors and sensors integrated into the environment. This article provides an overview of ubiquitous computing requirements and operational concept as well as pervasive services main characteristics. Consequently the key challenges facing the implementation and extension of ubiquitous computing as well as the main technologies used for this purpose are outlined. There are so many application domains that are adopting the ubiquitous computing concept; some of those will be presented. By the end of the research the author would like to give a good reference article that can help a lot of researchers interested in this field.
\end{abstract}

\section{Keywords}

Internet of Things, Pervasive computing, Sensor Networks, Ubiquitous computing.

\section{INTRODUCTION}

Ubiquitous computing can be considered as an advanced computing concept based upon the numerous technological advancements. Nowadays the whole world is moving towards "always connected" concept i.e. connected everywhere and anywhere, which leads directly to the Internet of Things "IoT" paradigm. IoT visionaries thought that all objects are becoming parts of the internet, where each object is uniquely identified and accessed through the network [1].

Ubiquitous computing concept lies under the umbrella of IoT technologies. In contrast to desktop computing, ubiquitous computing can be implemented and administrated using any device, at any location, in any format [2]. Fig. 1 shows IoT various application models.

A user can interact with the ubiquitous computing implementation using the underlying technology of many forms of every day used objects, including tablets, computer laptops, input/output devices, advanced middleware objects "e.g. sensors", location and positioning services, and of course the networking and internet services are mainly used in advance of all of the above technologies.
Ubiquitous computing is based on the concept that the more advances in technology leads directly to smaller size and much powerful computing equipment, that can be embedded ubiquitously and invisibly to human's environment.

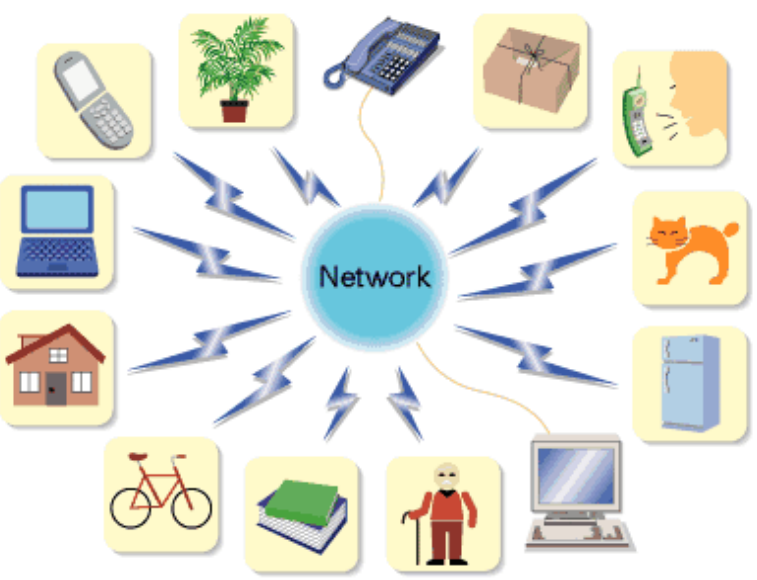

Fig. 1. IoT and Ubiquitous computing systems' various applications

Mark Weiser, chief technologist at XEROX-PARC (19881991) was the inventor and visionary of the ubiquitous computing concept, by defining and sketching out its major concerns [3]. Weiser presented a ubiquitous computing vision including three different classes of computing devices: tabs, pads, boards.

Each of these classes was like a new technology based substitute for an existing office instrument i.e. tabs was suggested to replace sticking notes as wearable centimeter sized devices, pads were similar to writing pads but in a wireless hand-held decimeter-sized devices pen-based form, and boards were wall sized interactive surfaces similar to white boards. Although the implementation of these systems didn't go anywhere further than the XEROX-PARC research labs, they had a significant impact on how people interact with technology.

Weiser's introduced implementation models that were based on wireless communications, distributed computing, context awareness concept, and embedded mobile devices [4]. These technologies have experienced a dramatic growth in the few past decades to reach out many practical domains that were not likely applicable. Ubiquitous computing osculates with a wide range of research topics, including the mentioned technologies and extended to mobile computing and networking, sensors networking, location and positioning computing, human-computer-interaction "HCI", and artificial intelligence "AI" [1]. 
In ubiquitous computing, there is a seamless integration between academic researches and advances in industry, which results in rapid adoption of academic researches outcomes in industry or wide range of available industrial schemes to support academic researches.

As per the topic literature review ubiquitous computing paradigm is also aliased as pervasive computing, everyware computing, ambient intelligence, haptic computing, and internet of things. Where systems are available anywhere and anytime, to anyone, where and when needed.

Pervasive computing requires involved services to have certain degree of computing capabilities built and integrated into them, and also these objects need to be able to communicate with each other to spread information to make our lives easier.

However, ubiquitous computing takes the process to the next step by making these objects to seamlessly interact with us and around us [1] [5] [8]. Practically, the differences between these terms is of an academic nature; they are commonly aiming to the goal of assisting people as well as the continuous improvement and promotion of economic and social processes by taking advantages of communicating with numerous microprocessors and sensors integrated into the environment [9].

In this article the author presents a literature review of ubiquitous computing, the remaining of the article will be organized as follows; section II will present the requirements and operational concepts. Main features and characteristics of the introduced paradigm will be discussed in section III. Section IV reviews challenges and vulnerabilities facing ubiquitous computing. Section V section describe some technology fields seem to be the most important for realization of the characteristics and requirements of ubiquitous computing. A general review of various applications depending on ubiquitous computing is presented in section VI. Section VII will present the author conclusions and future work as per the presented survey.

\section{UBIQUITOUS COMPUTING REQUIREMENTS AND OPERATIONAL CONCEPT}

Main operational features that uniquely characterize ubiquitous computing systems are:

- Situated in human personalized environments (PAN or BAN).

- Part of and used in sensing environmental parameters.

- Adopted by humans who can act cordially with the systems to control their own environments.

- According to Weiser's vision [5] in the previous review and mentioned operation features, the ubiquitous computing core requirements can be summarized as follows:

- Involved computerized devices need to be networked, distributed, and transparently accessible.

- More invisible Human-Computer-Interactions "HCI" are widely needed.

- Involved computerized devices need to be contextaware in order to optimize their operations within the environment.
- Involved computerized devices need to be selfcontrolled, autonomous, or operable with the minimum need for human interventions.

- Involved computerized devices need to handle intelligent decisions making and organizational interaction which may require some form of artificial intelligence.

- Involved computerized devices include small mobile computers, mobile telephones, "wearable's" like intelligent textiles or accessories, and computerized implants [9].

- If the ubiquitous computing system can handle these requirements then it is qualified to work in many types of environments, those can be classified into the following groups:

- Human related: personal social environment, or economic environment.

- Physical environment: of living things (interactive objects).

The mentioned requirements and working environments are not exclusive. They may be extended, overlapped, and combined [5].

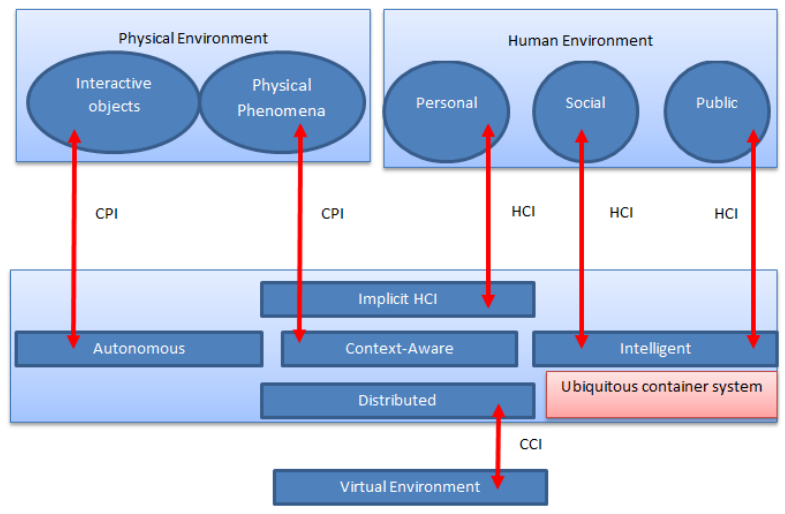

Fig. 2. Ubiquitous computing system model (technologies, environments, interaction).

\section{UBIQUITOUS COMPUTING SERVICES CHARACTERISTICS}

Ubiquitous computing systems are mainly aiming to provide certain types of services [5]. They are depending on the fundamental technologies explained in the previous section. Fig. 3 shows the main characteristics of ubiquitous computing integrated services [6].

- A service-oriented approach is required to develop and integrate applications from independent software units in a pervasive environment.

- Daily activities have to be explicitly described in Pervasive Service Composition for automatic system management. Users' activities occur in a pervasive computing environment. This nature affects the way the services are accessed.

- Service composition involves various kinds of information exchange. They include not only technical information for describing service input/output and interactions, but also managerial information for service peers and roles. That requires a shared understanding and interpretation 
of the information to smooth everyday activities within a pervasive computing environment.

- In pervasive computing, all kinds of services are relatively decentralized and independent. Therefore decentralization (democracy) is a significant feature in P2P-based composition.

- In pervasive service composition, trust management concerns with attaining a balance between availability and optimization and between automation and privacy control of applications.

- In Pervasive computing user is surrounded by many objects and entities. Sensing and interacting with those entities efficiently via wireless sensor networks enables adaptation of various applications.

- Automatic recognition and autonomous response of repetitive incidents without user intervention.

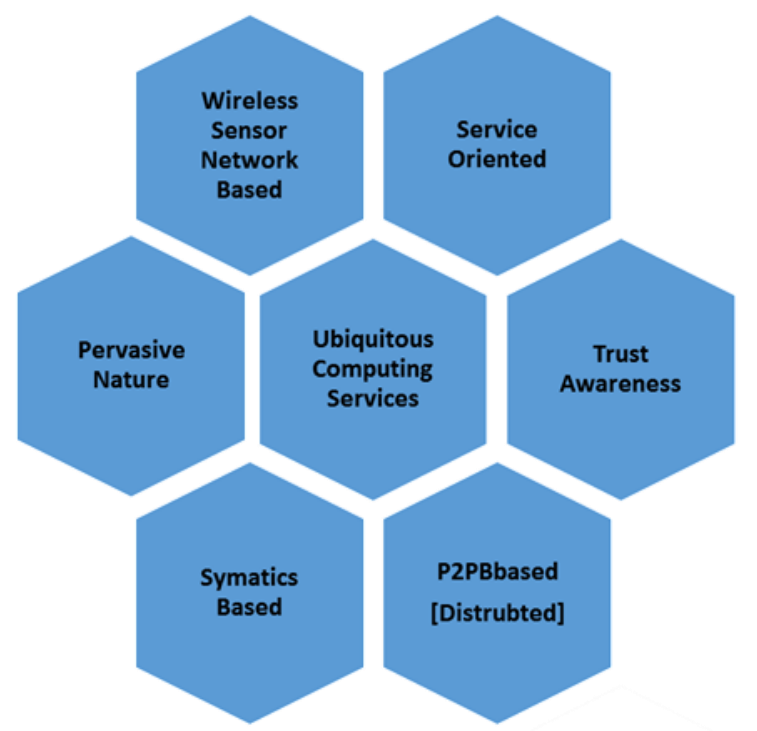

Fig. 3. Ubiquitous computing services characteristics

\section{UBIQUITOUS COMPUTING KEY CHALLENGES}

According to the previously discussed ubiquitous computing requirements, features, and services characteristics; some key challenges have been recognized regarding the implementation, security, HCI, etc. some of these challenges are discussed in this section [5] [7] [8]. Table I. presents ubiquitous computing challenges classification

\subsection{Hardware Specifications:}

New hardware manufacturing must be considered to have smaller sizes, lighter weights, and much more intelligent interaction which can cordially comply with the invisible HCI (iHCI) and autonomous ubiquitous system requirements [5].

\subsection{Security}

Security of ubiquitous computing system will be the most challenging issue. On one hand; we require the system to have the maximum intelligence and interaction capabilities to be able to respond on behalf of humans in some situations. Yet on the other hand we need our objects and entities to be secured and our privacy is granted. It is so vulnerable to allow the collection of personal information via sensor networks, which can be easily attacked and maliciously controlled. At the end the user might suffer a life threatening situation due to the ubiquitous system vulnerabilities.

\subsection{User's Lack of Control}

As explained in the previous review, one of the main requirements of ubiquitous computing system is to be autonomous and self-controlled. In this case the user might have the impression of being administrated by the system, and that the system's response regarding some situation might not be agreed on by the user [5].

\subsection{High-level Energy Management and Processing Capabilities}

Ubiquitous computing systems require high level of processing capabilities which in turn increases the energy demand in the user's computing space.

\subsection{Intelligence and Context-Awareness Capabilities}

Ubiquitous computing systems have to be minimally intrusive, so it must be able to recognize the user's state and behave accordingly. This behavior is adjustable according to the environmental readings and information received from wireless sensor network in each user's computing space, (for example: human vital signs, body temperature, heart rate, and so on). So a key challenge of ubiquitous computing system is to collect information needed to be processed in a contextaware manner.

\subsection{Standardization and Operability}

Ubiquitous computing deals with numerous amounts of hugely diverse technology platforms and objects. Ubiquitous computing systems must ensure that they act in a platform manner. Full integration and operability must be assured to avoid re-inventing the whole system for embedding a sensor or any new object

Table I. Ubiquitous computing challenges classification and categorization

\begin{tabular}{|c|c|c|}
\hline $\begin{array}{l}\text { Challe- } \\
\text { nge } \\
\text { Main } \\
\text { Catego- } \\
\text { ry } \\
\end{array}$ & $\begin{array}{c}\text { Challengin } \\
\text { g Feature }\end{array}$ & Challenge Description \\
\hline \multirow{2}{*}{ Devices } & $\begin{array}{l}\text { Heterogen- } \\
\text { eity }\end{array}$ & $\begin{array}{l}\text { Heterogeneous devices are required } \\
\text { to act seamlessly regardless of the } \\
\text { differences in hardware and } \\
\text { firmware capabilities [9]. }\end{array}$ \\
\hline & Mobility & $\begin{array}{l}\text { Maintaining network connectivity } \\
\text { for mobile devices is a main } \\
\text { concern of ubiquitous computing } \\
\text { systems. }\end{array}$ \\
\hline \multirow{2}{*}{$\begin{array}{l}\text { Softwa- } \\
\text { re } \\
\text { compo- } \\
\text { nents }\end{array}$} & $\begin{array}{l}\text { Mobility } \\
\text { and } \\
\text { distribution }\end{array}$ & $\begin{array}{l}\text { As the user can be mobile, the } \\
\text { software is required to be of mobile } \\
\text { and distributed mechanism. }\end{array}$ \\
\hline & $\begin{array}{c}\text { Context } \\
\text { awareness }\end{array}$ & $\begin{array}{l}\text { Software invisability to user must } \\
\text { be accomplished by repalcing } \\
\text { user's input with knowledge of } \\
\text { context. Like user activities, } \\
\text { location, time, and weather } \\
\text { conditions,...etc. }\end{array}$ \\
\hline
\end{tabular}




\begin{tabular}{|c|c|c|}
\hline & Adaptation & $\begin{array}{l}\text { Adaptation is required to harmonize } \\
\text { with the dynamic nature of } \\
\text { ubiquitous computing. }\end{array}$ \\
\hline & $\begin{array}{c}\text { Interopera } \\
\text { bility }\end{array}$ & $\begin{array}{l}\text { The infrastruscture of ubiquitous } \\
\text { computing must support diverse } \\
\text { and heterogeonous types of } \\
\text { software components }\end{array}$ \\
\hline & $\begin{array}{l}\text { Developm- } \\
\text { ent } \\
\text { and } \\
\text { deployment }\end{array}$ & $\begin{array}{l}\text { As the number of software } \\
\text { components required for ubiquitous } \\
\text { computing increases, the need to } \\
\text { find methods for rapid development } \\
\text { and deployment is non-negotiable. }\end{array}$ \\
\hline & Scalability & $\begin{array}{l}\text { Ubquity requires scalability. A } \\
\text { powerful software paltform which } \\
\text { can afford sacalability, fault } \\
\text { tolerance, and distribution features } \\
\text { is very essential. }\end{array}$ \\
\hline \multirow[b]{2}{*}{ Users } & Context & $\begin{array}{l}\text { System must be aware of user's } \\
\text { current circumstances. It should } \\
\text { adapt its behaviour according to the } \\
\text { user's current requirements. }\end{array}$ \\
\hline & Mobility & $\begin{array}{l}\text { Automatic migration should be } \\
\text { enabled as the user is being mobile } \\
\text { between devices. The migration } \\
\text { process should be tranparent as } \\
\text { possible. }\end{array}$ \\
\hline \multirow{2}{*}{$\begin{array}{l}\text { User } \\
\text { Interfa- } \\
\text { ces }\end{array}$} & $\begin{array}{l}\text { Universal } \\
\text { interfaces }\end{array}$ & $\begin{array}{l}\text { The GUI should be adaptable } \\
\text { according to the context and } \\
\text { circumstances of the user. Many } \\
\text { universal interfaces should be } \\
\text { developed to provide required } \\
\text { scalability. }\end{array}$ \\
\hline & Usability & $\begin{array}{l}\text { User interfaces for ubiquitous } \\
\text { computing applications should be } \\
\text { carefully designed to be result oriented } \\
\text { and enjoyable at the same time. Also it } \\
\text { should be developed for ordinary people } \\
\text { not just for techies. }\end{array}$ \\
\hline
\end{tabular}

\section{TECHNOLOGIES EMBEDED IN UBIQUITOUS COMPUTING}

Ubiquitous computing is not an independent technology. It is mainly depending on the integration between the characteristics of an invisible, ubiquitous, and seamless information and communication technologies.

In this section we will describe some technology fields seem to be the most important for realization of the previously mentioned characteristics and requirements of ubiquitous computing [10] [11] [12] [13].

\subsection{Microelectronics}

New hardware manufacturing must be considered to have smaller sizes, lighter weights, and much more intelligent interaction which can cordially comply with the invisible HCI (iHCI) and autonomous ubiquitous system requirements [5].

\subsection{Power Supplies}

Ubiquitous computing applications require heavy power supplying, although the consistently decreased system size.

Even so, for most applications the power supply is the largest and heaviest component, and the biggest constraint on its use, especially when dealing with mobile and wireless systems which require change or recharge the batteries on frequent bases.

Many embedded systems and wireless technology institutes are working on developing portable and alternative power sources [11].

\subsection{Sensor Technologies and Networks:}

The sensor is the core of capturing and analyzing the real world as one of the main characteristics of ubiquitous computing. It is the component that qualitatively or quantitatively certain environmental parameters and characteristics.

The key challenges in sensor development today include miniaturization size and weight of sensors; ensure integration of the sensors into one complex system, and reducing the power consumption [11] [12] [13].

Nowadays, Nanotechnology is following new approaches with radically smaller and further sensitive sensors. Sensor networks are now of a huge interest as a research topic [11].

\subsection{Communication Technology:}

The Institute of Electrical and Electronics Engineers (IEEE) has issued a number of different standards for wireless networks. The 802.11 standard is regulating wireless local area networks (WLANs). Bluetooth (IEEE 802.15.1) has become popular for communication between devices in a personal area networks (PANs). Many other approaches that will be vital in the development of mobile communication such as WiMAX (802.16 e/m), wireless USB, and Mobile Communications are standardized. Then it can be recognized that communication technology trends are key components in ubiquitous computing system.

\subsection{Localization Technology:}

Location-based services offer facilities based on the geographic locations of the users. There are currently three types of localization systems: satellite-based global positioning system (GPS) with positioning precision tends to 10 meters, cellular-supported with positioning precision vary between 0.1 and 35 kilometers, and indoor localization systems with positioning precision vary between 0.5 to 1 meter.

\subsection{Security Technology:}

Security is protecting confidentiality, integration, and availability of information assets from any intentional attack. Many security techniques are also used to ensure nonrepudiation, anonymity and authenticity.

Security is essential in ubiquitous computing. Most communications in ubiquitous computing are using wireless communications which makes the role of security more important because this type of communications can be manipulated easily.

There are some ubiquitous computing applications where security technology is not important; like some gaming or fun applications, or isolated (not network enabled) applications, where attacks are improbable [11].

\subsection{Machine-to-Machine and Human-to- Machine Communications}

The standardization of appropriate machine-machine interfaces and their development are thus extraordinarily important for ubiquitous computing. Machine-to-machine 
communication is moderately relevant in the domain of ubiquitous computing.

The human-to-machine interaction in ubiquitous computing domain is far beyond the dominant keyboard, monitor principles.

The main challenge in Human-to-Computer Interaction is to implement a semantic model of the real world, that allow the computer understand the human moves and talking. This would be very helpful in the field of health care using ubiquitous computing. Fig. 4. Shows Human-to-Machine Interaction Model [14].

\subsection{Smart Mobile Devices and Phones:}

Assimilation of multiple functionalities into a one mobile device is a mutual trend in today's mobile industry. Almost all new mobile phones have photo/video cameras, GPS navigation systems, full keyboards; support multiple wireless communications technologies, as well as running many applications supported by their operating system. A major feature of a pervasive computing system is to integrate into the environment and surround the users with its ubiquitous presence; smart phones can be the fundamental interface device that connects the user to the pervasive computing environment. However, it can be said that the manufacturing of smart phones with all its embedded features facilitated us to approach the implementation of pervasive technologies [1].

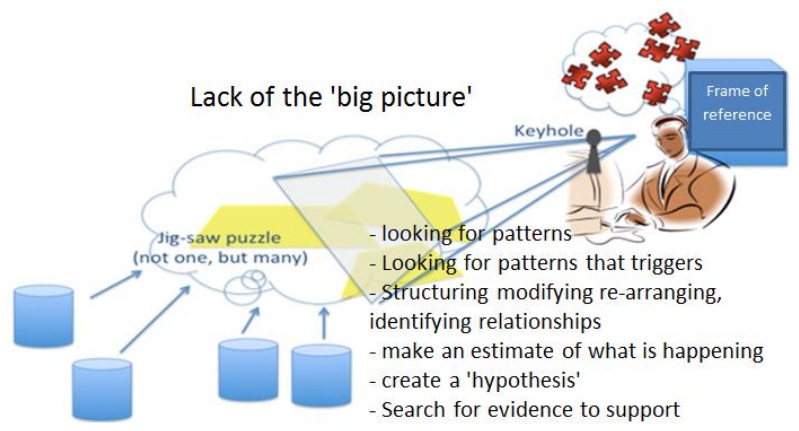

Fig. 4. Human-to-Machine Interaction Model [14]

\section{APPLICATIONS OF UBIQUITOUS COMPUTING}

Due to its crossing-boundaries nature, ubiquitous computing is currently involved in so many applications. As per the conducted survey, these applications can be categorized according to their impact-, to the following categories:

$$
\begin{array}{ll}
\text { - } & \text { Social } \\
\text { - Environmental } \\
\text { - Economic }
\end{array}
$$

This review will focus on some of the significant and pioneering applications as follows [2] [5] [10] [11]:.

\subsection{Merchandising or Retail:}

Applications in retailing are currently based on the use of cheap RFID Tags (instead of barcode labels), which are attached to product packaging or containers.

- Pros:

- It becomes possible to identify goods at any time and at any point along the supply chain.
- Based on this information, it is possible to predict supply and demand for certain products more quickly and accurately.

- Automatic registration and identification of goods deliveries.

- More efficient inventory management and the automatic recording of the inventory.

- Automatic recording of goods in the customer's shopping basket.

- Improved protection against theft.

- Cons:

- The scope for investing in new IT infrastructures and equipping products with RFID transponders is very restricted. Thus, RFID labels are still too expensive for many low priced goods or those with a very small profit margin.

Industrial Automation and Material Management:

The optimization of existing processes and increasing efficiency and productivity are the primary focus as well as the monitoring of raw materials, goods and intermediates.

Pros:

- Emerging production logistics, control of machines and equipment

- The optimization of the utilization and availability of production facilities.

- Replaces a great number of manual counting, scanning, data collection and control operations.

- $\quad$ Reduce waste and production stoppages caused by a lack of loading equipment.

- Almost completely avoid misdirected items

- Cons:

- A worldwide standardization of the technology and the data formats used would be beneficial

- The same situation as in merchandising, who can afford the required investments?.

\subsection{Exporting and Logistics:}

It is important to know where the goods are at any time. Ubiquitous computing is assisting in this issue, where transported objects are equipped with communication and computing capabilities, which will improve traceability in the supply chain.

Pros:

- Ubiquitous computing can enhance the logistics processes by the good planning and steering to the handling of goods and information flows.

- Automation and rationalization are necessary for firms in the international logistics business.

- The medium- to long-term goal is the creation of logistic networks, in which "intelligent objects" that detect their surroundings through advanced sensors can autonomously find their way to their recipients. 
Cons:

- They are similar to the mentioned in the previous two applications.

\section{Personal identification and authentication}

The proof of a person's identity is an important feature of many applications of ubiquitous computing.

Pros:

- Personal identification plays a primarily role in access control or payment procedures.

- Ground-breaking applications should not only depend on location and context awareness, but it must be tailored to suit every individual user.

- RFID implants, which are used explicitly in the longterm surveillance of "chipped" persons, even if this ostensibly serves a good purpose, such as preventing kidnappings.

Cons:

- In some cases very detailed patterns of movements and behavior can be collected which can be utilized against the user in case of non-secure applications.

\subsection{Health care}

Ubiquitous computing opens up possibilities for a better quality of healthcare. The applications have medium-to-long term implementation perspective, depending on the advances in technology of sensors and sensor networks.

For this purpose, the vital parameters and motion data of the patients are recorded; the home environment is also monitored. The necessary sensors can be integrated in clothing and the collected data is sent, which can be lifesaving in some emergency situations.

Pros:

- Automatic, remote and self-monitoring diagnoses for patients are granted.

- The quality of life for elderly and ill persons is improved at home.

Cons:

- Healthcare is undoubtedly the most challenging environment for introducing ubiquitous computing. Medical data are the most sensitive personal data and thus require strict data protection measures, such as organized access procedures, the prevention of transient data accesses or undesirable secondary use.

\subsection{Mobility and transport}

The use of ubiquitous computing in the area mobility and transportation is obviously noticed in integrated systems to control transport flows and to inform road-users. Starting from electronic tickets based on RFID, ending to navigation and traffic recording systems as well as the traditional traffic technologies, which are currently being provided by VANETs "vehicular ad hoc networks"

Pros:

- Increase safety during travel (state of vehicle, accident prevention)
- Optimize traffic flows (navigation, optimization of fuel consumption)

- Provide services for more comfort for passengers (location-dependent information, entertainment, Internet access).

Cons:

- A wide range of rejection for these applications could occur. In case of governmental adoption for these solutions, as it will have a huge impact the users' privacy, for example: monitoring and imposing sanctions upon drivers' breaches and violations.

\section{CONCLUSIONS AND FUTURE WORK}

Pervasive computing has been envisioned since 1989 by Mark Weiser. Despite the fact that 25 years have passed, still a lot of researches are adopting Weiser's vision and appending their researches to the ubiquitous computing. A lot of applications have been developed based on the concept of "always connected" i.e. connected everywhere and anywhere, which leads directly to the Internet of Things "IoT" paradigm. In IoT domain, all objects are becoming parts of the internet, where each object is uniquely identified and accessed through the network.

It is the human nature to go all-out for connection with other individuals, objects and activities, which can be fulfilled by pervasive environments providing access to ubiquitous information services.

Ubiquitous computing is depending on integrating many underlying technologies of many forms of every day used objects, including tablets, computer laptops, input/output devices, advanced middleware objects "e.g. sensors", location and positioning services. The main requirements and services characteristics of a successful ubiquitous computing based systems are: system should be accessible transparently; supporting all types of possible communications like (HCI, CCI, and CPI); autonomous, personalized, context-aware based responses should be designed and considered for less human intervention; user privacy should be granted; highlevel energy management and processing capabilities should be considered; full integration and operability of the system must be assured.

Many technologies are embedded in the field of Ubiquitous computing environments design and implementation. Microelectronics, communication technologies, power management technologies, security tactics, sensors industry, and location detection technologies are the most currently used technologies in Ubiquitous computing domain. All these technologies together with the concept of pervasive computing are now being used for the purpose of advancement in many existing applications and services for more human comfort and easiness of life style or better environmental and economic impacts. Although there are a lot of pros when using ubiquitous computing based applications but also there will be some cons need to be mitigated.

This research is aiming to put the ubiquitous computing topic main concerns all together as a research starting point. All the presented concerns will be closely explored in future researches and articles.

For the future the author is intending to focus on one the most important applications of pervasive computing (pervasive 
health care systems). "Towards an affordable real-time emergency detection and response for critical heart conditions" is their next research idea for the benefit of developing countries with limited health care resources

\section{REFERENCES}

[1] Bowman, M., Debray, S. K., and Peterson, L. L. 1993. S. Kurkovsky, "Pervasive Computing: Past, Present and Future (invited paper)," In Proceedings of The 5th International Conference on Information and Communication Technology (ICICT 2007), Cairo, Egypt, December 16-18, 2007, pp.68-73.

[2] Louis COETZEE, Johan EKSTEEN, "The Internet of Things - Promise for the Future? An Introduction," in Proc. of IST-Africa 2011 Conference, 2011K. Elissa.

[3] M. Weiser, "The Computer for the Twenty-first Century , Scientific American, Sep 1991pp. 94-10.

[4] M. Weiser, "Some Computer Science Issues in Ubiquitous Computing," Communications of the ACM, Vol. 36, Jul. 1993, pp. 75-84.

[5] Poslad, S. "Smart Devices and Services, in Ubiquitous Computing: Smart Devices, Environments and Interactions ," Chichester, UK: 2009, John Wiley \& Sons, Ltd.

[6] JiehanZhou , Ekaterina Gilman , Mika Ylianttila , JukkaRiekki, "Pervasive Service Computing: Visions and Challenges ," Proceedings of the 2010 10th IEEE International Conference on Computer and Information Technology, p.1335-1339, June 29-July 01, 2010.

[7] Ian Christie , "Pervasive Computing," IEEE Pervasive Computing, Jan.-Mar. 2010, pp. 25-30.

[8] M. Satyanarayanan, "Pervasive Computing Vision and Challenges," IEEE Personal Comm., vol. 6, no. 8, Aug. 2001, pp. 10-17.

[9] Henricksen K, Indulska J, Rakotonirainy, "Infrastructure for Pervasive computing: Challenges," Workshop on Pervasive Computing INFORMATIK 01, Viena, September 2010.

[10] Friedewald, M., Raabe, O., "Ubiquitous computing: An overview of technology impacts. "“ Telemat. Inf. 28(2), 55-65 (2011).

[11] JaydipSen, "Ubiquitous Computing: Applications, Challenges and Future Trends ," Book Chapter in "Embedded Systems and Wireless Technology: Theory and Practical Application", Editors: Raúl Aquino Santos and Arthur Edwards Block (University of Colima, Mexico), Chapter No. 1, pp. 1-40, CRC Press, Taylor \& Francis Group, USA, 2012. 